\title{
A positive return on investment: Research funding by the Thoracic Surgery Foundation for Research and Education (TSFRE)
}

\author{
David R. Jones, MD, ${ }^{a}$ Michael J. Mack, MD, ${ }^{\mathrm{b}}$ G. Alexander Patterson, MD, ${ }^{\mathrm{c}}$ and Lawrence H. Cohn, $\mathrm{MD}^{\mathrm{d}}$
}

\begin{abstract}
Objectives: The Thoracic Surgery Foundation for Research and Education (TSFRE) was formed in 1991 with the primary goals of generating new knowledge and nurturing the development of surgeon-scientists. The purpose of this article is to determine how effective the TSFRE has been in achieving these goals.
\end{abstract}

\begin{abstract}
Methods: A survey instrument was sent electronically to all former and current TSFRE research award recipients. Major themes included the benefits on TSFRE award recipients with respect to career choices of thoracic surgery, progress toward research independence, and the ability to leverage TSFRE funds to more substantive National Institutes of Health (NIH) awards. Success rates for NIH funding were confirmed using NIH Research Portfolio Online Reporting Tools.

Results: The total completed survey response rate was 70\% (75/107). The response rates for each group were as follows: resident 74\% (28/38), faculty 85\% (29/34), Braunwald 50\% (9/18), and TSFRE/NIH K-award 65\% (11/17). The funding rate for all grants was 14\% (90/619). For resident research awardees, $81 \%(34 / 42)$ are cardiothoracic surgeons or are thoracic surgery residents. The conversion rate for existing TSFRE/NIH co-sponsored $\mathrm{K}$-awards to R01 grants is $40 \%$ at 5 years compared with a $20 \% \mathrm{~K}$ to R conversion rate for all NIH K-award recipients. K to R conversion rates for junior faculty grant awardees without a prior K-award is $44 \%$, which is much higher than NIH rates for all new investigator R01 awards.
\end{abstract}

Conclusions: The return on investment for TSFRE funding for surgeon-scientists is resoundingly positive with respect to promoting careers in cardiothoracic surgery and to obtaining subsequent NIH funding for thoracic surgeon investigators. (J Thorac Cardiovasc Surg 2011;141:1103-6)

The Thoracic Surgery Foundation for Research and Education (TSFRE) was founded in 1991 by the 4 major thoracic surgical associations and societies. It is the primary mechanism through which the specialty of thoracic surgery supports the initial research efforts of residents interested in careers in thoracic surgery, as well as junior faculty members who have committed to having research as a critical part of their academic careers. The first TSFRE grants were awarded in 1993. TSFRE research award recipients are selected by the Foundation's research committee comprising 12 to 15 North American thoracic surgeons. Approximately 3 to 5 awards are given annually, with most awards being for 2 years' duration. All applicants receive a peer-reviewed scientific critique of their research plan regardless of the funding status of the proposal.

Since 1993 the TSFRE has made 90 awards totaling over $\$ 5$ million in awards to general surgery residents and young

\footnotetext{
From the Department of Surgery at the University of Virginia, ${ }^{a}$ Charlottesville, Va; Cardiothoracic Associates of North Texas, ${ }^{\text {b }}$ Dallas, Tex; Washington University, ${ }^{\text {c }}$ St Louis, Mo; and the Brigham and Women's Hospital, ${ }^{\mathrm{d}}$ Harvard University, Boston, Mass.

Disclosures: Authors have nothing to disclose with regard to commercial support. Received for publication Feb 5, 2011; accepted for publication March 16, 2011.

Address for reprints: David R. Jones MD, Professor of Surgery, Division Chief, Thoracic \& Cardiovascular Surgery, PO Box 800679, University of Virginia, Charlottesville, VA 22908-0679 (E-mail: djones@virginia.edu). $0022-5223 / \$ 36.00$

Copyright (c) 2011 by The American Association for Thoracic Surgery doi:10.1016/j.jtcvs.2011.03.010
}

academic thoracic surgeons. As part of these awards, the Nina S. Braunwald Award for women performing research in cardiovascular diseases was established in 1993 by her husband to honor his wife's legacy. To date, over $\$ 1.5$ million has been awarded to Braunwald recipients.

In 2002 the TSFRE partnered with the National Heart, Lung, and Blood Institute (NHLBI) and in 2005 the National Cancer Institute (NCI) to jointly sponsor Mentored Clinical Scientist Development Awards (K08) and Mentored Patient Oriented Research Career Development Awards (K23). These grant submissions receive the same National Institutes of Health (NIH) peer review as all other K-grants. TSFRE support is given only to funded recipients. Through this partnership, TSFRE was able to augment the salary support provided by the NHLBI or NCI for $17 \mathrm{~K}$-award recipients. Support from the TSFRE for this important collaboration with the NIH thus far has been $\$ 4.4$ million. Therefore, total TSFRE research support for 107 grants, including the Braunwald awards, over the past 18 years has been approximately $\$ 9.4$ million.

To date there has been no analysis of how effective the investment of Foundation support has been in achieving one of the primary goals of the TSFRE - to nurture and support young thoracic surgeon-scientists. In an effort to address the "return on investment" by the TSFRE with respect to the development of future thoracic surgeon-scientists, we designed a specific survey instrument to query TSFRE awardees on how effective the TSFRE was in achieving 


\section{Abbreviations and Acronyms \\ AATS $=$ The American Association for Thoracic Surgery \\ NCI $=$ National Cancer Institute \\ NHLBI $=$ National Heart, Lung, and Blood Institute \\ $\mathrm{NIH}=$ National Institutes of Health \\ STS $=$ The Society of Thoracic Surgeons \\ TSFRE $=$ The Thoracic Surgery Foundation for Research and Education}

this goal. The results and their implications are discussed in the subsequent report.

\section{METHODS}

A 33-item survey instrument was sent electronically to all former and current TSFRE research award recipients. This also included recipients of co-sponsored K-awards as well as all the Nina Braunwald recipients. Major themes contained within the survey included the role of TSFRE in positively promoting our specialty, the impact of scientific mentorship, the ability of awardees to apply for and obtain NIH awards (both K- and R- awards), and the current job descriptions of the resident and faculty awardees. Individuals who had been awarded more than 1 TSFRE grant were asked to complete only 1 survey. Two follow-up electronic reminders were sent to those individuals who had not completed the initial survey.

To confirm the success rates for NIH funding for the entire cohort of TSFRE awardees, we used the NIH Research Portfolio Online Reporting Tools. ${ }^{1}$ All TSFRE awardees were screened using this mechanism and the result and type of award (ie, K08, R01, R21) were documented. The American Association for Thoracic Surgery (AATS) and The Society of Thoracic Surgeons (STS) membership was confirmed through the respective association membership rosters. Membership was assigned to each specific group on the basis of the type of award given to the individual. The Research Portfolio Online Reporting Tools findings and the survey responses were then collated and analyzed.

\section{RESULTS \\ General Observations}

From 1993 to 2010, there were 619 grant submissions for resident, junior faculty, and Braunwald TSFRE awards. The average number of grants submitted annually is 39 (range 23-71). Ninety of these grants were awarded for an overall $14 \%$ funding rate. These included 38 resident fellowships, 34 junior faculty grants, and 18 Nina Braunwald grants. In addition to these funded grants, 17 NIH co-sponsored K08 and $\mathrm{K} 23$ grants were also awarded.

The total completed survey response rate was 70\% (75/ 107). The response rates for each group were as follows: resident $74 \%$ (28/38), faculty $85 \%$ (29/34), Braunwald $50 \%(9 / 18)$, and TSFRE/NIH K-award 65\% (11/17). Eighty percent of all awards were given to men. Race distribution for the 75 respondents was white $(65 \%)$, Asian (28\%), Hispanic (3\%), African American (1\%), and other $(3 \%)$. Eighty percent of TSFRE award recipients were between 35 and 50 years of age.

\section{Resident Research Fellowships}

One of the primary purposes for awarding research fellowships to general surgery residents is not only to instruct them in the scientific method, but also to introduce them to academic thoracic surgery. The results of our study show that $96 \%$ of resident grant awardees practice in an academic center, with nearly $50 \%$ having a faculty appointment. Over $75 \%$ of those who have a faculty appointment have their own laboratory and $32 \%$ have been successful in obtaining NIH funding, including R01, K08, and other awards. Perhaps more important, $77 \%$ of these fellowship awardees plan to apply to the NIH for funding in the future.

Interestingly, $85 \%$ of respondents believe that initial TSFRE funding was critical to launching their research careers. Moreover, $74 \%$ of respondents still collaborate with their scientific mentor and the majority of those respondents who are on the faculty have medical students and residents in their laboratories.

\section{Junior Faculty Grants}

Fourteen percent of the respondents in this category are women and $90 \%$ practice in an academic medical center (60\% adult cardiac and $40 \%$ general thoracic). The majority are assistant $(42 \%)$ or associate professors $(31 \%)$. With respect to how they spend their time, $60 \%$ spend $20 \%$ to $50 \%$ of their time in research with only $13 \%$ spending more than $50 \%$ of their time in research-related activities (Table 1).

Seventy percent of respondents have their own laboratory and $35 \%(12 / 34)$ have been successful in securing NIH funding. Specifically, of those receiving NIH funding, $75 \%$ (9/12) have had an R01 award, 17\% (2/12) have had a K-award, and $8 \%(1 / 12)$ have a U01 award (Table 1). Remarkably, for all junior faculty grant awardees from 1993 though 2006, $9(39 \%)$ of 23 have made the conversion from TSFRE funding to an R01 award. There has been a slight decrease in the current NIH funding levels for all junior faculty grant awardees, with only $8 \%$ and $58 \%$ of recipients having K08 and R01 awards, respectively. There are, however, 11 TSFRE faculty grant awardees (2007 to the present) who should soon have enough experience to apply for NIH K- or R-awards.

In addition to their other research interests, $62 \%$ of respondents have been a principal investigator for one or more clinical trials at their institution. They are participating members in their professional associations with solid membership rates in the STS $(76 \%)$ and the AATS $(47 \%)$. Over $80 \%$ of respondents believe the TSFRE award was critical to launching their research careers, and like the fellowship awardees, over $90 \%$ have medical students and general surgery residents in their laboratories. Finally, $71 \%$ of these respondents still collaborate with their TSFRE mentors and 78\% have encouraged residents in their own laboratories to apply for TSFRE funding. 
TABLE 1. Characteristics of TSFRE award recipients

\begin{tabular}{lcccc}
\hline \multicolumn{4}{c}{ TSFRE research award category } \\
\hline & Jesident & $\begin{array}{c}\text { Junior } \\
\text { faculty }\end{array}$ & Braunwald & $\begin{array}{c}\text { NIH } \\
\text { K08/23 }\end{array}$ \\
\hline $\mathrm{N}$ & 38 & 34 & 18 & 17 \\
Male/female & $32: 6$ & $33: 1$ & $0: 18$ & $16: 1$ \\
NIH funding (\%) & N/A & 35 & 22 & 100 \\
R01 funding (\%) & N/A & $39 *$ & 17 & $44 \dagger$ \\
$\geq$ 50\% of time spent in & 19 & 13 & 11 & 56 \\
$\quad$ research (\%) & & & & \\
PI of a clinical trial & 40 & 62 & 38 & 44 \\
Collaboration with & 74 & 71 & 71 & 67 \\
$\quad$ scientific mentor (\%) & & & & \\
STS membership (\%) & 55 & 76 & 55 & 94 \\
AATS membership (\%) & 10 & 47 & 28 & 53 \\
\hline
\end{tabular}

TSFRE, Thoracic Surgery Foundation for Research and Education; NIH, National Institutes of Health; PI, Principal investigator; STS, The Society of Thoracic Surgeons; AATS, The American Association for Thoracic Surgery. *Funding rate for all junior faculty from 1993 though 2006 . $†$ Either finished or have completed 4 years of their K-award.

\section{Braunwald Grants}

Applicants for the Braunwald award must be women with research proposals in cardiovascular or congenital heart disease. All of the respondents who are working are in academic surgery. A breakdown of respondent practice patterns reveals that $66 \%$ practice adult cardiac surgery, $16 \%$ surgery for congenital heart disease, and $16 \%$ are not practicing medicine at all. Unfortunately, $89 \%$ of Braunwald awardees spend less than $50 \%$ of their time doing research and $30 \%$ spend less than 1 day a week doing research (Table 1). Thirty-three percent of Braunwald recipients have their own laboratory, $38 \%$ have been the principal investigator on a clinical trial at their institution, and 4 $(22 \%)$ of 18 have been successful in obtaining NIH funding. As would be expected, all of these awards came through the NHLBI. Membership rates in the STS and AATS are 55\% and $28 \%$, respectively. Interestingly, $22 \%(4 / 18)$ of the Braunwald award recipients who were general surgery residents chose not to pursue a career in cardiothoracic surgery.

\section{TSFRE/NIH Co-Sponsored K-Awards}

Since its inception there have been $17 \mathrm{~K}$-awards cosponsored by the NIH and the TSFRE. Interestingly, only $12 \%(2 / 17)$ of $\mathrm{K}$-awardees had a history of any type of prior TSFRE funding. Only 1 woman has been a recipient of this K-award co-sponsorship. At the NHLBI there have been 18 applications with 12 funded (66\% funding rate) and at the NCI there have been 20 applications with only 5 funded ( $25 \%$ funding rate). There have been 3 successful K23 awards and all these are funded through the NCI. On average, $4 \mathrm{~K}$-grants are submitted annually to the NIH by cardiothoracic surgeons who checked the box on the NIH application to receive matching funds from the TSFRE.
In what is likely an honest assessment, only $56 \%$ of the respondents spend $50 \%$ or more of their time performing research. Of the $9 \mathrm{~K}$-award recipients who have either finished or have completed 4 years of their K-award, 4 $(44 \%)$ have converted it to an R01 award with all awards coming from the NHLBI.

\section{DISCUSSION}

The degree of discretionary funding to support surgical researchers has decreased significantly as physician reimbursement rates from insurance carriers, including the Center for Medicare and Medicaid Services, has decreased significantly over the past 20 years. Current expectations for both faculty salary support and revenues to the medical center mandate that the majority of faculty effort be devoted to patient care. ${ }^{2}$ In addition to the demands of clinical practice, the number of thoracic surgeons who are performing research is thought to have decreased over the past decade. ${ }^{3}$ This is clearly related to linking physician remuneration to the generation of relative value units which, in our specialty, directly correlates to increasing time and effort. The domino effect of fewer surgical scientists is that there are then fewer appropriately trained mentors for residents and students interested in cardiothoracic surgical research. The importance of these mentor-mentee relationships is well documented and is further supported in this study, where over $70 \%$ of respondents still collaborate with their mentor and $70 \%$ have residents or students in their own research laboratories.

Unequivocal measures of the success of the TSFRE program are its ability to foster academic careers, to promote sustained interest in the discipline of cardiothoracic surgery, and to help produce the next generation of extramurally funded thoracic surgeon-scientists. Evidence for the impact of TSFRE on the first 2 goals is that $87 \%$ of TSFRE awardees practice in academic medical centers. In addition, of the 42 resident research awardees (including some residents who were Braunwald awardees) from 1993 to 2008, 81\% (34/ 42) are cardiothoracic surgeons or are currently in a thoracic surgery residency program. It is impossible to ascertain whether residents working in thoracic surgeon-scientist's laboratories were committed to a career in thoracic surgery before their research experience. It is our belief; however, that one reasonable interpretation is that some residents who were initially undecided about a career choice were convinced that cardiothoracic surgery would be a rewarding career after completing their research experience.

Our study also strongly supports the positive impact of TSFRE funding on helping support the next generation of extramurally funded thoracic surgeon-scientists. Recent analyses by the NIH suggest that from 1972 to 2008 the conversion rates from K08 to R01 awards after the first year of the $\mathrm{K} 08$, for all institutes, regardless of principal investigator specialty, are $20 \%, 43 \%$, and $47 \%$ at 5,10 , and 15 years, respectively. ${ }^{1}$ Although there are no current data on 
$\mathrm{K}$ to $\mathrm{R}$ conversion rates specific to cardiothoracic surgeons, data presented in this report demonstrate that $44 \%$ of our co-sponsored NIH/TSFRE K-awardees now have R01 funding at an average of 5 years from the first year of their K08 award. This compares very favorably with the $20 \% \mathrm{~K}$ to $\mathrm{R}$ conversion rate at 5 years for all NIH K-award recipients noted above. Further evidence of the impact on TSFRE funding facilitating NIH R01 awards for junior faculty members without prior $\mathrm{K}$-award funding is the nearly $40 \%$ R01 funding rate, which is extraordinarily high. This is contrasted to the fiscal year 2010 R01 funding rate of $20 \%$ for all new investigators, regardless of degree (ie, $\mathrm{MD}, \mathrm{PhD}$, or $\mathrm{MD} / \mathrm{PhD}$ ), $\mathrm{NIH}$ institute, or prior K-award. ${ }^{1}$

Although these observations regarding the impact of TSFRE funding on thoracic surgeon-scientist career development are certainly positive and reinforcing, the percent effort dedicated to research as reported by the study respondents is far too low to maintain viable research programs or for thoracic surgeons to move from mentored to independent research careers. This is most certainly related to the heavy demands of clinical care on the researcher, as previously discussed. Failure to address this culture, however, will undoubtedly contribute to even fewer applications to the NIH, which has been shown by Ratcliffe and associates ${ }^{4}$ to be the primary determinant of the decreased per capita funding for cardiothoracic surgeons relative to the entirety of the $\mathrm{NIH} .{ }^{4}$

Careful analysis of this report also reveals 2 obvious and important opportunities for improvement going forward. First, the percent of women TSFRE awardees, particularly at the junior faculty $(14 \%)$ and the TSFRE/NIH cosponsored $\mathrm{K}$-award $(6 \%)$ levels, is unacceptably low. One reason for this is the relatively small numbers of women faculty in academic cardiothoracic surgery, which results in fewer applications for research funding to the TSFRE and to the NIH. Other reasons include a lack of female scientific mentors and role models for both female thoracic surgeons and female general surgery residents. The other observation from this study is the poor correlation between award of a Braunwald grant and a future research career in academic surgery. The attrition rate away from research careers of Braunwald awardees certified by the American Board of Thoracic Surgery appears to be too high. Only $22 \%(4 / 18)$ of individuals have received NIH funding (3 R01 and 1 K08 awards). When only cardiothoracic surgeons (not the 4 general surgery residents who received the award) are considered, the rate improves to $29 \%(4 / 14)$, which is better. Although one interpretation of these data would be that better selection of the Braunwald awardee may improve subsequent returns on that investment, other, perhaps more plausible, reasons exist. These include the pressures of having and raising children and, once in practice, the lack of female surgical mentors and colleagues, which can lead to isolation and disillusionment regarding the importance of research in their careers.

The limitations of this type of study include the selfreporting associated with survey instruments, failure to have all TSFRE awardees participate in the study, and the lack of a control group. It is unlikely that the respondents overstated the positive and more subjective aspects of the award. With respect to the possibility of reporting inaccurate NIH funding success, the secondary assessment using the NIH Research Portfolio Online Reporting Tools ${ }^{1}$ should have obviated that possibility. There was a $71 \%$ overall response rate, which is actually very good for studies such as this. A survey of over 30 large e-mail surveys demonstrated an overall response rate of only $38 \%{ }^{5}$ It is also possible that the lower response rate $(50 \%)$ from the Braunwald awardees may possibly introduce an inaccurate reporting of the effect of TSFRE funding on that group. Finally, although there is no possibility of a control group in a study of this type, we were able to compare the $\mathrm{K}$ to $\mathrm{R}$ conversion rates and overall R01 funding rates of our TSFRE grant recipients to similar groups from the NIH database.

In summary, the results of this study on the impact of TSFRE funding on the career development and academic success of cardiothoracic surgeons suggests that this mechanism of support is meeting, and in some cases exceeding, the goals of the Foundation. The return on investment of TSFRE funding is robust and needs to be continued and supported. Remarkably, over $80 \%$ of general surgery residents funded through TSFRE have chosen a career in cardiothoracic surgery. Almost $90 \%$ of respondents reported that TSFRE funding was critical to launching their research careers. TSFRE awardees have a very high rate of obtaining R01 funding (with or without an initial K-award) relative to NIH data on R01 applicant funding success rates. Finally, this study suggests several opportunities to improve the TSFRE funding mechanism, but also highlights the importance of our specialty in continuing to support all thoracic surgical scientists, particularly women.

\section{References}

1. NIH Research Portfolio Online Reporting Tools (RePORT) (http://report.nih.gov/ index.aspx).

2. Ozomaro U, Gutierrez JC, Bryne MM, Zimmers TA, Koniaris LG. How important is the contribution of surgical specialties to a medical school's NIH funding? $J$ Surg Res. 2007;141:16-21.

3. Orandi BJ, Blackburn S, Henke PK. Surgical mentors' and mentees' productivity from 1993 to 2006. Am J Surg. 2011;201:260-5.

4. Ratcliffe MB, Howard C, Mann M, del Nido P. National Institutes of Health funding for cardiothoracic surgical research. J Thorac Cardiovasc Surg. 2008;136:392-7.

5. Sheehan KB. E-mail survey response rates: a review. J Comp Media Comm. 2001; 6:0. doi: 10.1111/j.1083-6101.2001.tb00117.x. 